\title{
Ventriculosubgaleal shunt and neuroendoscopic lavage: refining the treatment algorithm of neonatal post-hemorrhagic hydrocephalus
}

\author{
Paolo Frassanito ${ }^{1}$ (D) $\cdot$ Francesca Serrao $^{2} \cdot$ Francesca Gallini $^{2,3} \cdot$ Federico Bianchi $^{1} \cdot$ Luca Massimi $^{1} \cdot$ Giovanni Vento $^{2,3}$. \\ Gianpiero Tamburrini ${ }^{1,3}$
}

Received: 29 March 2021 / Accepted: 13 May 2021 / Published online: 20 May 2021

(C) The Author(s) 2021

\begin{abstract}
Background The optimal management of neonatal post-hemorrhagic hydrocephalus (PHH) is still debated, though several treatment options have been proposed. In the last years, ventriculosubgaleal shunt (VSgS) and neuroendosdcopic lavage (NEL) have been proposed to overcome the drawbacks of more traditional options, such as external ventricular drainage and ventricular access device.

Methods We retrospectively reviewed neonates affected by PHH treated at our institution since September 2012 to September 2020. Until 2017 patients received VSgS as initial treatment. After the introduction of NEL, this treatment option was offered to patients with large intraventricular clots. After NEL, VSgS was always placed. Primary VSgS was reserved to patients without significant intraventricular clots and critically ill patients that could not be transferred to the operating room and undergo a longer surgery.

Results We collected 63 babies (38 males and 25 females) with mean gestational age of 27.8 \pm 3.8 SD weeks (range 23-38.5 weeks) and mean birthweight of $1199.7 \pm 690.6 \mathrm{SD}$ grams (range 500-3320 g). In 6 patients, hemorrhage occurred in the third trimester of gestation, while in the remaining cases hemorrhage complicated prematurity. This group included 37 inborn and 26 outborn babies. Intraventricular hemorrhage was classified as low grade (I-II according to modified Papile grading scale) in 7 cases, while in the remaining cases the grade of hemorrhage was III to IV. Mean age at first neurosurgical procedure was $32.2 \pm$ 3.6SD weeks (range 25.4-40 weeks). Death due to prematurity occurred in 5 patients. First-line treatment was VSgS in 49 patients and NEL in the remaining 14 cases. Mean longevity of VSgS was 30.3 days (range 10-97 days) in patients finally requiring an additional treatment of hydrocephalus. Thirty-two patients required one to three redo VSgS. Interval from initial treatment to permanent shunt ranged from 14 to 312 days (mean 70.9 days). CSF infection was observed in 5 patients (7.9\%). Shunt dependency was observed in 51 out of 58 surviving patients, while 7 cases remained shunt-free at the last follow-up. Multiloculated hydrocephalus was observed in 14 cases. Among these, only one patient initially received NEL and was complicated by isolated trapped temporal horn.

Conclusions VSgS and NEL are two effective treatment options in the management of PHH. Both procedures should be part of the neurosurgical armamentarium to deal with $\mathrm{PHH}$, since they offer specific advantages in selected patients. A treatment algorithm combining these two options may reduce the infectious risk and the risk of multiloculated hydrocephalus.
\end{abstract}

Keywords Hemorrhage $\cdot$ Hydrocephalus $\cdot$ Neuroendoscopic lavage $\cdot$ Personalized medicine $\cdot$ Preterm $\cdot$ Ventriculosubgaleal shunt

Paolo Frassanito

paolo.frassanito@gmail.com

1 Pediatric Neurosurgery, Fondazione Policlinico Universitario A. Gemelli IRCCS, Largo Agostino Gemelli, 8, 00168 Rome, Italy

2 Neonatal Intensive Care Unit, Fondazione Policlinico Universitario A. Gemelli IRCCS, Rome, Italy

3 Catholic University Medical School, Rome, Italy

\section{Introduction}

Neonatal post-hemorrhagic hydrocephalus (PHH) is a complication of intraventricular hemorrhage (IVH) in preterm babies [1] or, less frequently, of fetal intracranial hemorrhage [2]. Transient treatment of hydrocephalus is required by the presence of blood clot within the CSF and the characteristics of the preterm baby that contraindicate the placement of a permanent 
CSF shunting device. Several treatment options have been proposed, though the consensus on the best treatment option is still to be reached $[3,4]$.

In this context, ventriculo subgaleal shunt (VSgS) has emerged in the last years as a solution reducing the infectious risk and allowing to control hydrocephalus until the patient reaches an adequate body weight and the CSF clarifies [5]. More recently, neuroendoscopic lavage (NEL) has been adopted as an alternative treatment option warranting a significantly reduced risk of shunt dependency and multiloculated hydrocephalus [6-9], with good neurodevelopmental outcome [10].

We sought to develop a treatment algorithm that implements both procedures, focusing our attention on the selection of patient candidate to VSgS with or without NEL.

\section{Materials and method}

We retrospectively collected neonatal patients affected by PHH treated at the Fondazione Policlinico Universitario A. Gemelli IRCCS, Rome, Italy, since September 2012 to September 2020. Charts were reviewed for demographic, clinical, and surgical data. Until 2017, all patients were initially treated by VSgS. After the introduction of NEL, indication to $\mathrm{VSgS}$ versus NEL+VSgS was carefully based on the preoperative US evaluation and clinical conditions of the baby. In fact, $\mathrm{VSgS}$ was indicated in cases with small intraventricular clots and preserved communication between lateral and third ventricles, warranting drainage of the ventricular system by a single ventricular catheter. On the other hand, NEL+VSgS was indicated in case of large intraventricular clots, aiming to prevent multiloculated hydrocephalus. Main contraindication to NEL+VSgS was represented by critical general conditions requiring treatment in the intensive care unit, without any possibility to transfer the patient to the surgical theater.

\section{Surgical technique}

\section{VSgS}

Our surgical technique for placement of $\mathrm{VSgS}$ has been extensively described elsewhere [11]. The procedure is performed in the surgical theater or in the intensive care unit according to the general conditions of the baby. Endotracheal intubation is not required, since the procedure lasts less than $15 \mathrm{~min}$, and it is avoided whenever feasible.

After careful disinfection and sterile draping, an L-shaped incision is performed in the right pre-coronaric area. This incision warrants adequate skin covering over the device, also at the time of redo $\mathrm{VSgS}$, and can be easily converted in a Cshaped incision at the time of shunt conversion. A small burr hole is made using a No. 20 scalpel blade on the anterior angle of the bregmatic fontanelle, followed by dural opening and cortical coagulation. A large subgaleal pouch is harvested before ventriculostomy with blunt dissection of the subgaleal space in the ipsilateral parietal region. The device is prepared using an antibiotic-impregnated catheter (Bactiseal Codman, Integra Lifesciences, North Billerica, Billerica, MA, USA) with the interposition of a right-angle connector. The distal end is left open with additional holes in the ending segment of the tube (Fig. 1). After ventriculostomy, the device is placed and the subgaleal pouch is continuously irrigated with bodytemperature saline solution to avoid the risk of abrupt drainage of the ventricles and secondary hemorrhage. Skin closure is performed with 5.0 running suture and skin glue. Transfontanellar ultrasounds (US) examination is performed to rule out immediate post-operative complications.

\section{NEL}

The surgical technique has been extensively described in the literature $[6,7]$. In the operating theater, the patient is placed supine with the head fixed in formed cotton diapers while under general anesthesia. The lateral ventricle with the largest solid hematoma is identified with transfontanellar US examination. After skin preparation, a lateralized frontal burr hole is made and the endoscope Decq (Storz, Tuttlingen, Germany) is inserted into the lateral ventricle. Irrigation of the ventricular system with $37{ }^{\circ} \mathrm{C}$ warmed Ringer solution is initiated. As appearing anatomic landmarks allowed for orientation, an interventricular septostomy is performed with tulium laser (Revolix jr, LISA laser products, Berlin, Germany) to allow irrigation of the contralateral ventricle. Solid hematoma components are aspirated by applying controlled suction with a syringe connected to the endoscopic aspiration tube, thus allowing stepwise aspiration of solid hematomas until the interface to the cerebral parenchyma was reached. The third and both lateral ventricles are cleared. Irrigation is stopped as soon as all accessible hematoma parts are aspirated and the intraventricular fluid becomes clear. After removal of the endoscope, a VSgS is placed, as previously described. The transcortical channel around the catheter is sealed with a gelatin sponge (Spongostan; Johnson \& Johnson Medical, New Brunswick, NJ, USA). The sponge is designed as a ring around the vertical part of the right-angle connector, aiming to reduce the risk of intraventricular migration of the device and of the sponge [12]. The skin is meticulously closed as described above.

\section{Postoperative management}

Postoperatively, all patients are transferred to the neonatal intensive care unit. Lateral positioning contralaterally to the subgaleal pouch is recommended, thus avoiding 
Fig. 1 Preterm baby with large and tense anterior fontanelle and diastased sutures (A). US showing $\mathrm{PHH}$ without significant intraventricular clots (B).

Ventriculo-subgaleal shunt harvested using an antibioticimpregnated catheter and a right angle connector $(\mathrm{C})$. Immediate postoperative picture with filled subgaleal pouch (D, shadowed area with white asterisk) and US showing correct placement of ventricular catheter (arrow) and resolution of hydrocephalus (E). (Image modified from Frassanito et al. "How to perform a ventriculo-subgaleal shunt", Springer [11])

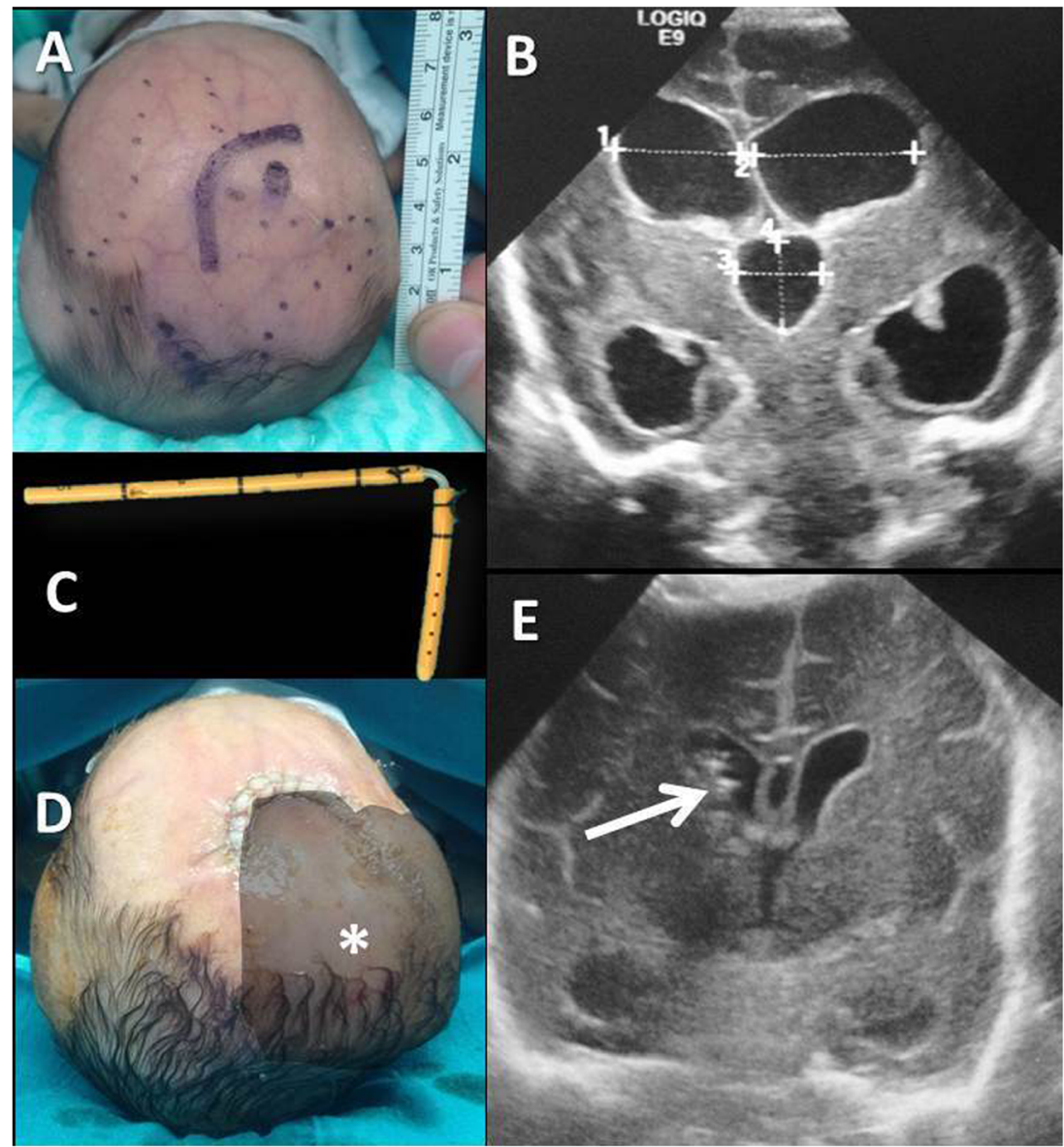

compression of the pouch. Clinical examination monitoring the tension of the subgaleal pouch and the head circumference is performed daily, while wound care as well as transfontanellar US are accomplished every third day. If clinical signs of active hydrocephalus reoccur, due to $\mathrm{VSgS}$ malfunction (collapsed subgaleal pouch or tense subgaleal pouch), conversion to permanent ventriculoperitoneal shunt is considered if general clinical conditions are stable, patient's weight is over $2000 \mathrm{~g}$, and hemorrhage is solved on US/MR. In case of previous abdominal surgery, conversion to ventriculo-atrial shunt is indicated and it is performed if the diameter of the jugular vein is adequate and patient's weight is over $5000 \mathrm{~g}$.

Revision of $\mathrm{VSgS}$ is performed if patient is not suitable for conversion into permanent shunt. If $\mathrm{VSgS}$ is revised, the device is replaced exploiting the same frontal access and harvesting a new subgaleal pouch on the opposite side or in a site that was not dissected before. In case of conversion to permanent shunt, the shunt is placed exploiting the existing frontal access. Finally, patient may be discharged with working VSgS and monitored into outpatient clinic every other week with transfontanellar US. In case of collapsed pouch without recurrent hydrocephalus, $\mathrm{VSgS}$ is surgically removed, thus making the patient shunt-free.

\section{Results}

We collected 63 babies ( 38 males and 25 females) with mean gestational age of $27.8 \pm 3.8 \mathrm{SD}$ weeks (range 23-38.5 weeks) and mean birthweight of $1199.7 \pm 690.6 \mathrm{SD}$ grams (range 500-3320 g). In 6 patients, hemorrhage occurred in the third trimester of gestation, while in the remaining cases hemorrhage complicated prematurity. This group included 37 inborn and 26 outborn babies. Intraventricular hemorrhage was classified as low grade (I-II according to modified Papile grading scale) in 7 cases, while in the remaining cases the grade of hemorrhage was III to IV. Mean age at first neurosurgical procedure was $32.2 \pm 3.6 \mathrm{SD}$ weeks (range 25.4-40 weeks). Death due to prematurity and related complications was registered in 5 patients.

First-line treatment was VSgS in 49 patients and NEL in the remaining 14 cases. Mean time of $\mathrm{VSgS}$ was 30.3 days, ranging from 10 to 97 days in patients finally requiring an additional treatment of hydrocephalus. Thirty-two patients required one to three redo $\mathrm{VSgS}$. Additional treatments in patients receiving VSgS as first treatment were NEL in 4 cases, EVD in 9 cases, and other endoscopic procedures for fenestration of intraventricular septa in 3 cases. One patient was complicated by subdural hygroma, requiring conversion of 
the VSgS into a subduro-subgaleal shunt (Fig. 2A-B). One patient was complicated by symptomatic upward transtentorial herniation at the time of redo $\mathrm{VSgS}$, treated by a second VSgS draining the trapped fourth ventricle.

Time from initial treatment to permanent shunt ranged from 14 to 312 days (mean 70.9 days). Interestingly, 20 patients were discharged with $\mathrm{VSgS}$.

CSF infection was observed in 5 patients (7.9\%). In particular, infection finally complicated CSF leak in three cases who underwent several procedures for treatment of multiloculated hydrocephalus before the introduction of NEL (Fig. 2C-F). In the remaining two cases, CSF infection was secondary to sepsis resulting from severe necrotizing enterocolitis.

Shunt dependency was observed in most of the cases with conversion to ventriculo-peritoneal shunt in 43 cases and ventriculo-atrial shunt in 8 cases. Seven cases remained shunt-free at the latest follow-up; two of them received ETV at the time of $\mathrm{VSgS}$ removal.

Multiloculated hydrocephalus was observed in 14 cases, requiring isolated aqueductoplasty in 4 cases, septostomy in 2 cases, fenestration of trapped temporal horn in 2 cases, and fenestration of multiple intraventricular septa/cysts in the 6 remaining cases. Among these, only one patient initially received NEL and was complicated by isolated trapped temporal horn.
With regard to the implementation of NEL in our treatment algorithm, thirty-nine patients were treated in the first part of our experience $(\mathrm{VSgS})$ and 24 after the introduction of the new protocol $(\mathrm{VSgS} \pm \mathrm{NEL})$. Results are presented in Table 1 .

\section{Discussion}

The treatment of neonatal PHH is still challenging due to the fragility of patients and other critical factors. Indeed, features of either the patient, namely prematurity and low weight, and the CSF, such as the blood clots and high protein concentration, and the receiving site of extrathecal CSF shunting, that are necrotizing enterocolitis for the abdomen and inadequate caliber of jugular vein in case of ventriculo-atrial shunt, require transient treatment of hydrocephalus, thus delaying the timing of permanent shunt until the previous conditions are solved.

External ventricular drainage (EVD) may be inserted at bedside, theoretically warrants continuous CSF drainage, and can be easily removed [13]. These advantages are counterbalanced by the ineluctable infectious risk. Additionally, adequate subcutaneous tunnel could be not performed, subcutaneous tissue is loose and poor, and the skin is loose, these factors favoring CSF leak and pullout of the
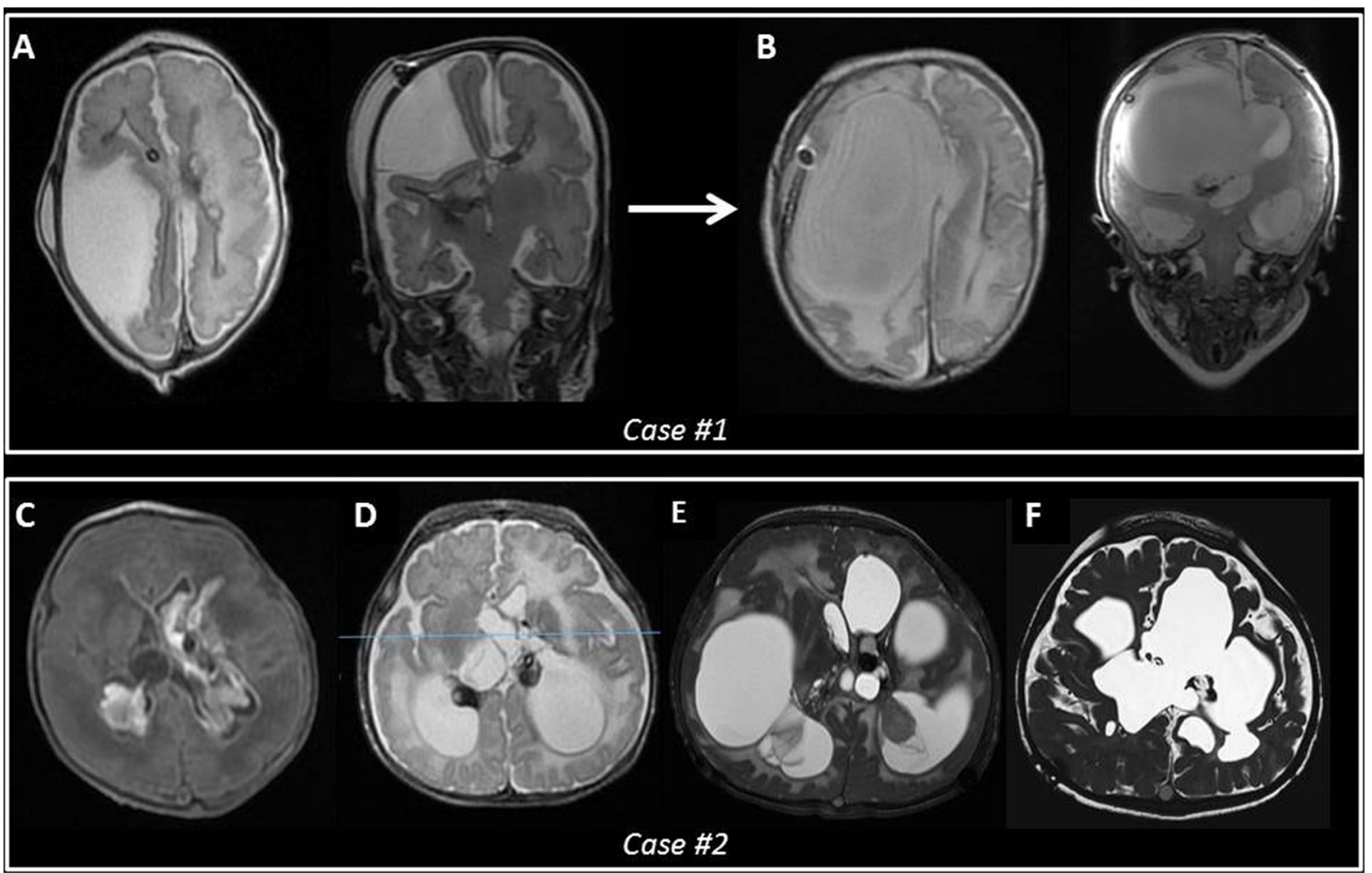

Fig. 2 Complications of VSgS. Case \#1-MR showing working VSgS with collapsed right ventricle and large extra-axial collection (A). Conversion of VSgS to subduro-subgaleal shunt allowed progressive re-expansion of the ventricle and drainage of the subdural hygroma (B). Case \#2-Preterm intraventricular hemorrhage, causing hydrocephalus that was treated by VSgS (C), before the introduction of NEL, and complicated by bilateral entrapment of ventricular horn (D), that required several additional endoscopic procedures with CSF leak and infection leading to multiloculated hydrocephalus (E). Last follow-up MR after endoscopic fenestration of intraventricular septa and VP shunt $(\mathrm{F})$ 
catheter. Other drawbacks are the low-pressure drainage, the frequent obstruction of the catheter by clot, and the presence of multiple lines that complicate the management of the patient and increase the risk of accidental pullout. Finally, risks of overdrainage and hyponatremia are not negligible. Antibiotic-impregnated catheter [14] and subcutaneous sutureless device have been implemented in our practice to reduce the risk of EVD $[15,16]$. However, mean time to conversion to permanent shunt is longer than 2 months in the present series, thus suggesting the cumulative risk of relying on EVD for such a long time.

On these grounds, we reserve EVD to patients with infection of CSF or blood, who could not receive VSgS.

Ventricular access device (VAD) partly overcomes limits of EVD $[17,18]$, but repeated tapping of the subcutaneous reservoir is burdened by ineluctable risk of infection and raises concerns on the alternate control of raised intracranial pressure.

These considerations prompted us to adopt $\mathrm{VSgS}$ in the management of PHH. Indeed, this treatment option proved to be effective and safe. Main advantages of VsgS are avoiding the risk of electrolyte imbalance secondary to CSF drainage, the easiness to manage the patient by the nursing and medical staff after adequate education, and the possibility to discharge the patient to home before permanent treatment of hydrocephalus. Furthermore, the length of the procedure is usually less than $15 \mathrm{~min}$ and could be performed at the bedside.

Infectious risk seems lower compared to other treatment options, namely EVD and VAD. It is of worth to note that series of $\mathrm{VSgS}$ reporting no infection include less than 20 patients $[19,20]$, while the risk of infection is constant in larger series [3,21-23] and ranges from 8 to $10 \%$ in series with more than fifty patients $[24,25]$ (Table 2).
Other complications are hemorrhage, due to abrupt drainage of ventricular system, and subdural hygroma hematoma.

Skin dehiscence with device exposure and CSF leak may be secondary to loose skin. Additionally, VSgS shares mechanical complications, such as obstruction and migration, with other shunt devices [26].

Technical aspects of VSgS are not standardized through the literature, in particular concerning the use of valve versus valveless tube and the use of reservoir. The use of valve may reduce the risk of abrupt drainage of the ventricular system and related complications, but it is associated to a major risk of obstruction by blood clot and collapsed subgaleal pouch. On these grounds, daily pumping is recommended by centers using VSgS with valve [20,24].

Additionally, the management of VSgS when subgaleal pouch is satured varies across the literature. In the majority of experiences, tapping of the pouch or of the reservoir is performed to extend the life of the VSgS. This somehow converts the $\mathrm{VSgS}$ into a ventricular access device and may affect the comparison of morbidity between the two options [23].

In our experience, we designed a bundle exploiting antibiotic-impregnated catheter and avoiding to tap the device or the pouch aiming to reduce infectious risk. Indeed, infection is the only factor, along with entity of brain damage by the initial hemorrhage, affecting the neurocognitive outcome of these patients [27]. Additionally, CSF infection critically contributes to the occurrence of complex forms of multiloculated hydrocephalus, thus furtherly complicating the management of PHH [28, 29].

Our management protocol of VSgS warranted an acceptable risk of infection, though this risk is ineluctable as the device and CSF could be infected secondarily to blood sepsis.

With the present no-tapping policy, the mean life expectancy of $\mathrm{VSgS}$ is about 32 days and it could be not compared to

Table 1 Characteristics of patients treated with VSgS (2012-2017) or VSgS \pm NEL (2018-2020)

\begin{tabular}{llll}
\hline & Total & VSgS & VSgS \pm NEL \\
\hline Patients & 63 & 39 & 24 \\
GA (range) & $27.8 \pm 3.8$ SD weeks & $27.6 \pm 4$ SD weeks & $28.7 \pm 3.4$ SD weeks \\
& $(23-38.5 \mathrm{w})$ & $(23-38.5 \mathrm{w})$ & $138.5 \mathrm{w})$ \\
Weight (range) & $1199.7 \pm 690.6 \mathrm{SD}$ grams $(500-3320 \mathrm{~g})$ & $1147.3 \pm 675.2 \mathrm{SD}$ grams & $1306 \pm 687.2 \mathrm{SD}$ grams \\
& & $(530-3320 \mathrm{~g})$ & $32.7 \pm 3.2 \mathrm{SD}$ weeks \\
GA at first surgery (range) & $32.2 \pm 3.6 \mathrm{SD}$ weeks $(25.4-40 \mathrm{w})$ & $32 \pm 3.8 \mathrm{SD}$ weeks & $(28.1-38.3 \mathrm{w})$ \\
& & $(25.4-40 \mathrm{w})$ & $1(4.2 \%)$ \\
Infection & $5(7.9 \%)$ & $4(10.3 \%)$ & $5(20.8 \%)$ \\
Multiloculated hydrocephalus & $14(22.2 \%)$ & $9(23.1 \%)$ & $1(4.2 \%)$ \\
Multiple intraventricular septations & $6(9.5 \%)$ & $5(12.8 \%)$ & $1(4.2 \%)$ \\
Death & $5(7.9 \%)$ & $4(10.3 \%)$ & 3 \\
Shunt-free & 7 & 4 & $87 \%$ \\
Shunt dependency & $87.9 \%$ & $8.6 \%$ & $37 \%$ \\
\hline
\end{tabular}




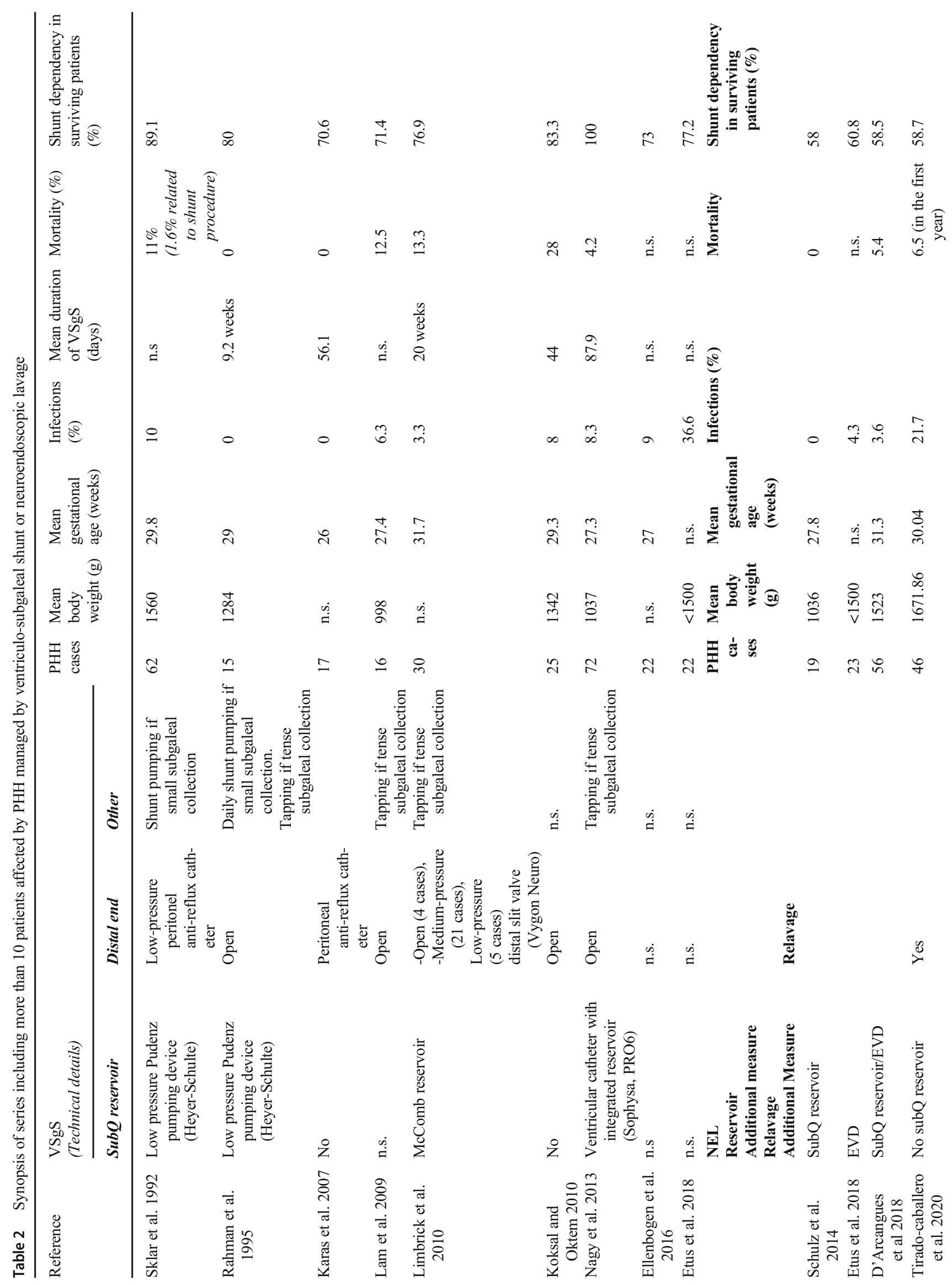


other experiences using daily tapping to extend the life of VSgS after saturation of the subgaleal pouch.

Other complications, secondary to abrupt drainage of the ventricular system, such as subdural hygroma and intraventricular hemorrhage occurred in the initial phase of this experience.

Some surgical nuances, as accurate choice of the side of ventriculostomy avoiding area with very thin brain parenchymal thickness and continuous irrigation of the subgaleal pouch during skin closure, helped to prevent these complications.

This retrospective analysis revealed three cases complicated by primary CSF infection without general sepsis before the introduction of NEL. Risk factors were several surgical and endoscopic procedures for multiloculated hydrocephalus and CSF leak. Indeed, the presence of large intraventricular clots favored a bilateral entrapment of temporal horns.

On these grounds, we implemented NEL in our management algorithm of PHH to prevent multiloculated complications and related morbidity (Fig. 3), as supported by literature data [6].

These treatment options have been proposed as alternative options by different neurosurgical centers. However, VSgS and NEL may have different indications and should be both available in the surgical armamentarium of pediatric neurosurgeons.

VSgS may be placed in the intensive care unit [19], thus representing an effective option for patients with critical clinical conditions contraindicating the transfer to the surgical theater and a longer surgical procedure, such as NEL. In our experience, this condition was usually observed in inborn patients with lower birthweight and more severe prematurity. Furthermore, $\mathrm{VSgS}$ may effectively control hydrocephalus in patients with xantocromic CSF without large intraventricular clots. Conversely, we observed this condition in particular in outborn patients, who were transferred to our institution after stabilization of clinical conditions and were treated at elder age compared to inborn patients. In these cases, treatment of $\mathrm{PHH}$ was easier due to spontaneous resolution of blood clots inside the ventricles and elder age of the baby at treatment, though this condition has been recently associated to worse outcome [30].

On the other side, NEL should be performed in the surgical theater and it reduces the risk of multiloculated hydrocephalus in patients with large intraventricular clots (Fig. 4). This treatment option is offered to babies with stable general conditions.

Literature data also show that NEL could significantly reduce the rate of shunt dependency [6]. However, this effect was not confirmed by the present experience, showing a rate of shunt dependency over $80 \%$, similarly to previous series of VSgS, and without significant difference between patients undergoing NEL and patients undergoing VSgS as first treatment. Further studies with larger numbers are advocated to 


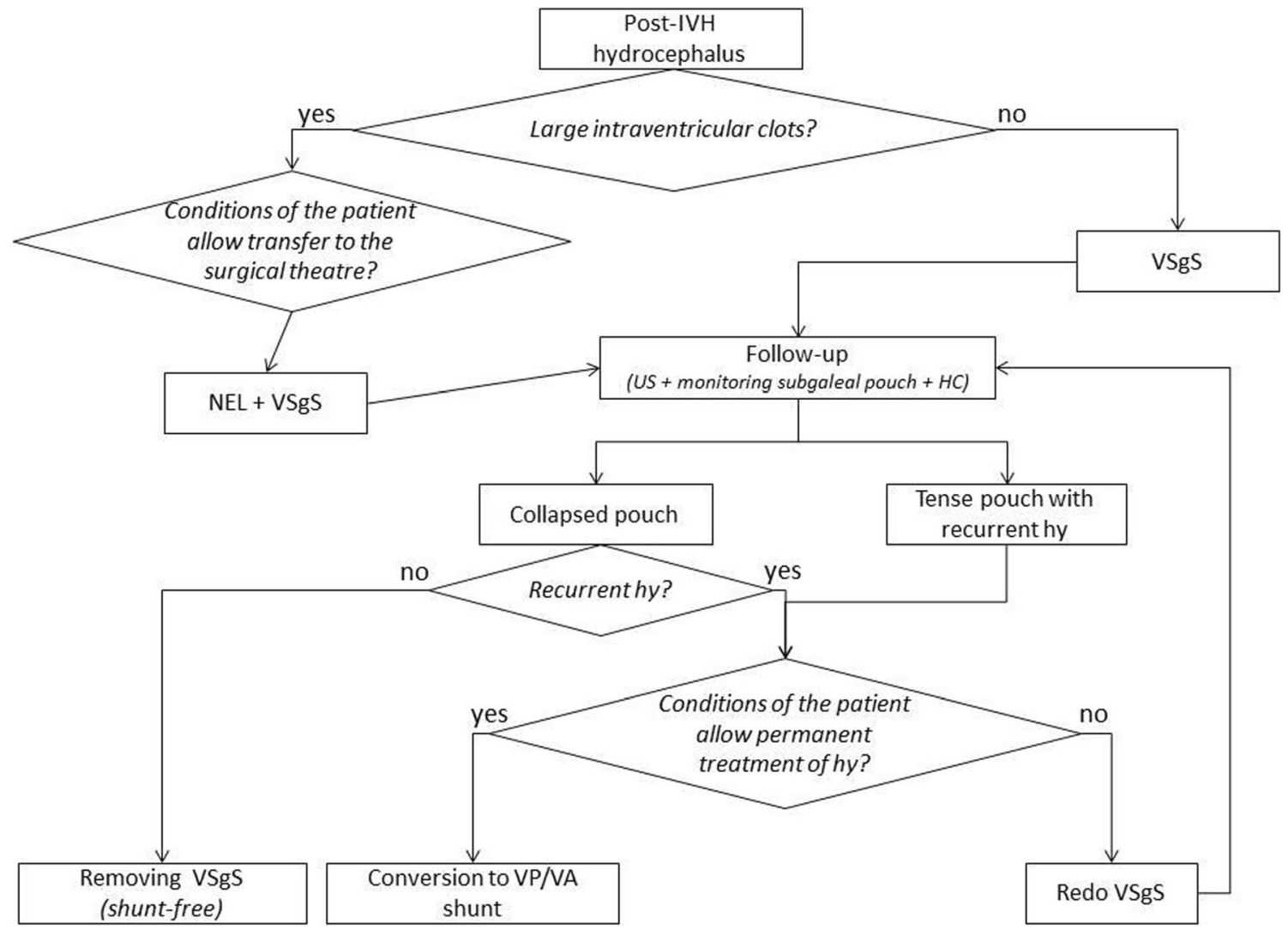

Fig. 3 Management algorithm of post-intraventricular hemorrhage (IVH) hydrocephalus

analyze the impact of other factors, such as the selection of patients and timing of surgery on this outcome measure.

In conclusion, this study represents the first institutional experience combining $\mathrm{VSgS}$ and NEL in the management of PHH. Although longer follow-up is required to study the neurocognitive outcome of these patients [10], these data would be essential to discuss the results of the ongoing TROPHY registry study, aiming to finally define the best management of PHH and standardize its treatment [4].

\section{Conclusions}

VSgS and NEL are two effective treatment options in the management of $\mathrm{PHH}$. Both procedures should be part of the

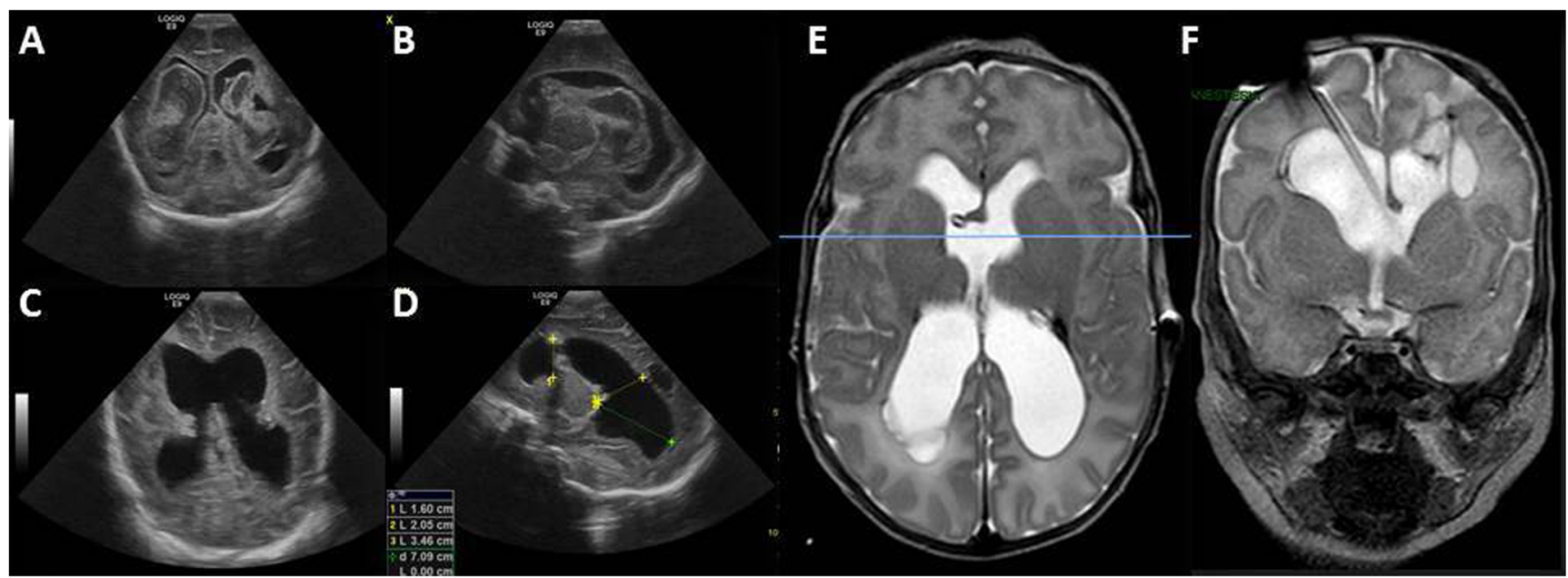

Fig. 4 Preoperative transfontanellar US showing PHH with large intraventricular clots (A, B) that were completely removed with NEL, as confirmed by postoperative US (C, D). MR after conversion of VSgS to VP shunt ruling out multiloculated hydrocephalus (E, F) 
neurosurgical armamentarium to deal with $\mathrm{PHH}$, since they offer specific advantages in selected patients. A treatment algorithm combining these two options may reduce the infectious risk and the risk of multiloculated hydrocephalus.

Funding Open access funding provided by Università Cattolica del Sacro Cuore within the CRUI-CARE Agreement.

\section{Declarations}

Conflict of interest The authors declare that are no conflict of interest to disclose.

Open Access This article is licensed under a Creative Commons Attribution 4.0 International License, which permits use, sharing, adaptation, distribution and reproduction in any medium or format, as long as you give appropriate credit to the original author(s) and the source, provide a link to the Creative Commons licence, and indicate if changes were made. The images or other third party material in this article are included in the article's Creative Commons licence, unless indicated otherwise in a credit line to the material. If material is not included in the article's Creative Commons licence and your intended use is not permitted by statutory regulation or exceeds the permitted use, you will need to obtain permission directly from the copyright holder. To view a copy of this licence, visit http://creativecommons.org/licenses/by/4.0/.

\section{References}

1. Klebe D, McBride D, Krafft PR, Flores JJ, Tang J, Zhang JH (2020) Posthemorrhagic hydrocephalus development after germinal matrix hemorrhage: established mechanisms and proposed pathways. J Neurosci Res 98:105-120. https://doi.org/10.1002/jnr.24394

2. Dunbar MJ, Woodward K, Leijser LM, Kirton A (2021) Antenatal diagnosis of fetal intraventricular hemorrhage: systematic review and meta-analysis. Dev Med Child Neurol 63:144-155. https:// doi.org/10.1111/dmcn.14713

3. Ellenbogen JR, Waqar M, Pettorini B (2016) Management of posthaemorrhagic hydrocephalus in premature infants. J Clin Neurosci 31:30-34. https://doi.org/10.1016/j.jocn.2016.02.026

4. Thomale U-W, Cinalli G, Kulkarni AV, al-Hakim S, Roth J, Schaumann A, Bührer C, Cavalheiro S, Sgouros S, Constantini S, Bock HC (2019) TROPHY registry study design: a prospective, international multicenter study for the surgical treatment of posthemorrhagic hydrocephalus in neonates. Childs Nerv Syst 35:613619. https://doi.org/10.1007/s00381-019-04077-4

5. Eid S, Iwanaga J, Oskouian RJ, Loukas M, Jerry Oakes W, Shane Tubbs R (2018) Ventriculosubgaleal shunting-a comprehensive review and over two-decade surgical experience. Childs Nerv Syst 34:1639-1642. https://doi.org/10.1007/s00381-018-3887-6

6. d'Arcangues C, Schulz M, Bührer C, Thome U, Krause M, Thomale UW (2018) Extended experience with neuroendoscopic lavage for posthemorrhagic hydrocephalus in neonates. World Neurosurg 116:e217-e224. https://doi.org/10.1016/j.wneu.2018. 04.169

7. Schulz M, Bührer C, Pohl-Schickinger A, Haberl H, Thomale UW (2014) Neuroendoscopic lavage for the treatment of intraventricular hemorrhage and hydrocephalus in neonates. J Neurosurg Pediatr 13:626-635. https://doi.org/10.3171/2014.2.PEDS13397
8. Tirado-Caballero J, Rivero-Garvia M, Arteaga-Romero F, HerreriaFranco J, Lozano-Gonzalez Á, Marquez-Rivas J (2020) Neuroendoscopic lavage for the management of posthemorrhagic hydrocephalus in preterm infants: safety, effectivity, and lessons learned. J Neurosurg Pediatr 26:1-10. https://doi.org/10.3171/ 2020.2.PEDS2037

9. Etus V, Kahilogullari G, Karabagli H, Unlu A (2018) Early endoscopic ventricular irrigation for the treatment of neonatal posthemorrhagic hydrocephalus: a feasible treatment option or not? A Multicenter Study. Turk Neurosurg 28:137-141. https://doi.org/ 10.5137/1019-5149.JTN.18677-16.0

10. Behrens P, Tietze A, Walch E, Bittigau P, Bührer C, Schulz M, Aigner A, Thomale UW (2020) Neurodevelopmental outcome at 2 years after neuroendoscopic lavage in neonates with posthemorrhagic hydrocephalus. J Neurosurg Pediatr 26:1-9. https://doi.org/ 10.3171/2020.5.PEDS20211

11. Frassanito P, Peraio S, Massimi L (2020) How to perform a ventriculo-subgaleal CSF shunt. In: Di Rocco C, Pang D, Rutka J (eds) Textbook of pediatric neurosurgery. Springer, Cham

12. Ktari O, Frassanito P, Gessi M, Bianchi F, Tamburrini G, Massimi L (2020) Gelfoam migration: a potential cause of recurrent hydrocephalus. World Neurosurg 142:212-217. https://doi.org/10.1016/ j.wneu.2020.06.214

13. Zucchelli M, Lefosse M, Corvaglia L, Martini S, Sandri F, Soffritti S, Ancora G, Mammoliti P, Gargano G, Galassi E (2016) Introduction of percutaneous-tunneled transfontanellar external ventricular drainage in the management of hydrocephalus in extremely low-birth-weight infants. J Neurosurg Pediatr 18:1-6. https://doi.org/10.3171/2016.1.PEDS15563

14. Tamburrini G, Massimi L, Caldarelli M, Di Rocco C (2008) Antibiotic impregnated external ventricular drainage and third ventriculostomy in the management of hydrocephalus associated with posterior cranial fossa tumours. Acta Neurochir 150:1049 1055; discussion 1055-1056. https://doi.org/10.1007/s00701-0080022-6

15. Frassanito P, Auricchio AM, Antonucci J, Massimi L, Bianchi F, Tamburrini G (2020) Securing CSF catheters to the skin: from sutures and bolt system to subcutaneous anchoring device towards zero complications. Childs Nerv Syst 36:2749-2755. https://doi. org/10.1007/s00381-020-04737-w

16. Frassanito P, Massimi L, Tamburrini G, Pittiruti M, Doglietto F, Nucci CG, Caldarelli M (2016) A new subcutaneously anchored device for securing external cerebrospinal fluid catheters: our preliminary experience. World Neurosurg 93:1-5. https://doi.org/10. 1016/j.wneu.2016.05.045

17. Kumar N, Al-Faiadh W, Tailor J et al (2017) Neonatal posthaemorrhagic hydrocephalus in the UK: a survey of current practice. Br J Neurosurg 31:307-311. https://doi.org/10.1080/ 02688697.2016 .1226260

18. Li D, Romanski K, Kilgallon M, Speck S, Bowman R, DiPatri A, Alden T, Tomita T, Lam S, Saratsis AM (2021) Safety of ventricular reservoir sampling in pediatric posthemorrhagic hydrocephalus patients: institutional experience and review of the literature. $\mathrm{J}$ Neurosci Nurs 53:11-17. https://doi.org/10.1097/JNN. 0000000000000566

19. Karas CS, Baig MN, Elton SW (2007) Ventriculosubgaleal shunts at Columbus Children's Hospital: neurosurgical implant placement in the neonatal intensive care unit. J Neurosurg 107:220-223. https://doi.org/10.3171/PED-07/09/220

20. Rahman S, Teo C, Morris W, Lao D, Boop FA (1995) Ventriculosubgaleal shunt: a treatment option for progressive posthemorrhagic hydrocephalus. Childs Nerv Syst 11:650-654. https:// doi.org/10.1007/BF00300724

21. Köksal V, Öktem S (2010) Ventriculosubgaleal shunt procedure and its long-term outcomes in premature infants with post- 
hemorrhagic hydrocephalus. Childs Nerv Syst 26:1505-1515. https://doi.org/10.1007/s00381-010-1118-x

22. Lam HP, Heilman CB (2009) Ventricular access device versus ventriculosubgaleal shunt in post hemorrhagic hydrocephalus associated with prematurity. J Matern Fetal Neonatal Med 22:10971101. https://doi.org/10.3109/14767050903029576

23. Limbrick DD, Mathur A, Johnston JM, Munro R, Sagar J, Inder T, Park TS, Leonard JL, Smyth MD (2010) Neurosurgical treatment of progressive posthemorrhagic ventricular dilation in preterm infants: a 10-year single-institution study. J Neurosurg Pediatr 6:224-230. https://doi.org/10.3171/2010.5.PEDS1010

24. Sklar F, Adegbite A, Shapiro K, Miller K (1992) Ventriculosubgaleal shunts: management of posthemorrhagic hydrocephalus in premature infants. Pediatr Neurosurg 18:263-265. https://doi.org/10.1159/000120673

25. Nagy A, Bognar L, Pataki I, Barta Z, Novak L (2013) Ventriculosubgaleal shunt in the treatment of posthemorrhagic and postinfectious hydrocephalus of premature infants. Childs Nerv Syst 29:413-418. https://doi.org/10.1007/s00381-012-19685

26. Tubbs RS, Banks JT, Soleau S, Smyth MD, Wellons JC III, Blount JP, Grabb PA, Oakes WJ (2005) Complications of ventriculosubgaleal shunts in infants and children. Childs Nerv Syst 21:48-51. https://doi.org/10.1007/s00381-004-0967-6

27. Vinchon M, Dhellemmes P (2006) Cerebrospinal fluid shunt infection: risk factors and long-term follow-up. Childs Nerv Syst 22: 692-697. https://doi.org/10.1007/s00381-005-0037-8

28. Peraio S, Amen MM, Ali NM, Zaher A, Mohamed Taha AN, Tamburrini G (2018) Endoscopic management of pediatric complex hydrocephalus. World Neurosurg 119:e482-e490. https://doi. org/10.1016/j.wneu.2018.07.187

29. Gandhoke GS, Frassanito P, Chandra N, Ojha BK, Singh A (2013) Role of magnetic resonance ventriculography in multiloculated hydrocephalus. J Neurosurg Pediatr 11:697-703. https://doi.org/10. 3171/2013.2.PEDS12456

30. Parodi A, Giordano I, De Angelis L et al (2021) Post-haemorrhagic hydrocephalus management: Delayed neonatal transport negatively affects outcome. Acta Paediatr 110:168-170. https://doi.org/10. 1111/apa.15604

Publisher's note Springer Nature remains neutral with regard to jurisdictional claims in published maps and institutional affiliations. 